\title{
Vitamin D in active systemic lupus erythematosus and lupus nephritis: a forgotten player
}

\author{
Marwa K. Khairallah ${ }^{1 *}$ (D), Yasmine S. Makarem² and Marwa A. Dahpy ${ }^{3}$
}

\begin{abstract}
Background: Systemic lupus erythematosus (SLE) is an autoimmune disorder associated with immunological abnormalities (Aringer et al., Arthritis Rheumatol 71:1400-1412, 2019). Vitamin D (VD) has an important role in SLE pathogenesis, as it controls cell cycle progression besides its anti-proliferative effects (Liu et al., J Cell Commun Signal 71, 2019). Determining the relationship between VD with SLE activity and lupus nephritis (LN) can establish a new role for VD in SLE management (Liu et al., J Cell Commun Signal 71, 2019). In our study, we aimed to assess the relationship between levels of VD in patients with SLE activity and with LN and to verify the relationship between VD levels with clinical and laboratory parameters in those patients, in order to assess the validity of adding serum VD level in the routine follow-up as a marker that may lead to earlier diagnosis of SLE activity and LN in adult SLE patients.

Results: Serum VD was significantly lower in SLE patients $(3.38 \pm 2.55 \mathrm{ng} / \mathrm{ml})$ versus healthy controls $(5.36 \pm 2.88$ $\mathrm{ng} / \mathrm{ml})(P<0.002)$. Interestingly, serum VD was significantly lower in patient with active SLE according to SLEDAI $(3.00 \pm 2.27 \mathrm{ng} / \mathrm{ml})$ versus those with inactive SLE $(5.10 \pm 3.19 \mathrm{ng} / \mathrm{ml})(P<0.02)$. Significant negative correlation was found between serum level of VD and each of mucocutaneous, malar rash, and renal manifestations. Significant negative correlation was also noticed among SLEDAI $(P$ value $=0.01)$ and renal SLEDAI scores $(P$ value $=0.021)$ with serum level of VD.

Conclusion: Low levels of VD were found to be frequent in SLE patients especially during phases of SLE activity and nephritis. Potent markers of low serum VD level in SLE patients were found to be mucocutaneous, malar rash, and LN. Our results support that VD levels could act as independent risk factors for activity and LN in SLE patients; moreover, treatment with VD supplementation could decrease the incidence of activity and nephritis in SLE patients.
\end{abstract}

Keywords: SLE, Lupus nephritis, Vitamin D

\section{Background}

The systemic lupus erythematosus (SLE) is an inveterate immunological disorder that is characterized by abnormal inflammatory processes affecting numerous systems [1]. Recent studies postulate that aberrant apoptosis and/or necrosis encountered in SLE result from exposure of the immune system to nuclear antigens and

\footnotetext{
* Correspondence: Marwa.kamal82@hotmail.com

'Nephrology Unit, Internal Medicine Department, Faculty of Medicine, Assiut University Hospital, Assiut University, Assiut, Egypt

Full list of author information is available at the end of the article
}

uptake of immune complexes by dendritic cells causing activation of interferon type-I overexpression [2]. The resulting inflammatory process leads to the development of $\mathrm{T}$ cells into pro-inflammatory pathways and thus producing autoantibodies [3].

Vitamin D (VD) is considered to be one of the most important lipid-soluble vitamins. It has an important role in phosphorus and calcium homeostasis and mineralization of bone [3]. After the conversion of 7-dehydrocholesterol into pre-VD3 in the skin, the body utilizes VD in addition to the smaller amounts of VD that come from the diet [4]. The

\section{Springer Open}

() The Author(s). 2020 Open Access This article is licensed under a Creative Commons Attribution 4.0 International License, which permits use, sharing, adaptation, distribution and reproduction in any medium or format, as long as you give appropriate credit to the original author(s) and the source, provide a link to the Creative Commons licence, and indicate if changes were made. The images or other third party material in this article are included in the article's Creative Commons licence, unless indicated otherwise in a credit line to the material. If material is not included in the article's Creative Commons licence and your intended use is not permitted by statutory regulation or exceeds the permitted use, you will need to obtain permission directly from the copyright holder. To view a copy of this licence, visit http://creativecommons.org/licenses/by/4.0/. 
major circulating form of VD is 25-hydroxycholecalciferol $(25(\mathrm{OH}) \mathrm{D})$; thus, the total serum $25(\mathrm{OH}) \mathrm{D}$ level is currently considered the best indicator of VD supply to the body from cutaneous synthesis and nutritional intake [2]. Recently, it has been found that multiple immune cells express VD receptors (VDRs) on their surfaces [5], and several immune cells synthesize $1 \alpha$-hydroxylase enzyme needed for the synthesis of an active form of VD in lymph tissues [6]. These results suggest that VD is implicated in immune modulation $[7,8]$. Several researchers tried to identify possible relations between VD and SLE. Commonly, fatigue, psychological symptoms, and musculoskeletal disorders are associated with SLE, as well as low serum VD [9]. On the contrary, other researches claimed no association between active SLE and VD levels [10].

Systemic lupus erythematosus clinical aspects are variable and target renal, respiratory, dermatological, and musculoskeletal systems [11]. Lupus nephritis occurs in about $50 \%$ of SLE patients. Active LN can be the first manifestation in 30\% of the patients [11], and $10-30 \%$ of SLE patients may present with renal failure within 10 years [12]. Impaired renal function can intervene with 1hydroxylation that is important to produce active VD $[8$, 13]. We aimed to assess the relationship between levels of VD in SLE patients with and without activity and specially LN and to determine the relationship among VD levels, laboratory, and clinical findings in those patients.

\section{Methods}

The current study is a cross-sectional, prospective observational study that was carried out at the Nephrology Unit in the Internal Medicine department and Rheumatology, Rehabilitation, and Physical Medicine department in collaboration with the Medical Biochemistry department at Faculty of Medicine, Assiut University, during the period from January 2018 to January 2020. The study was carried out on 100 Egyptian SLE patients. All were diagnosed according to Systemic Lupus International Collaborating Clinics (SLICC) [14]. Sixty-six healthy age- and sex-matched controls were enrolled in the study. A written consent to participate in the study was signed by each participant. The study was approved by the Institutional Review Board of Faculty of Medicine (IRP No. 17300432).

We included patients older than 18 years suffering from SLE who fulfilled four or more criteria (at least one clinical and one laboratory criterion) or biopsy-proven LN with positive antinuclear antibodies or anti-DNA according to SLICC, while patients with other systemic autoimmune diseases and/or with urinary tract infection ( $\geq 100,000$ colony-forming units in urine culture) and those undergoing hemodialysis or with a history of renal transplantation were excluded from the study.
All participants were subjected to clinical assessment through full history taking, systemic, and local examinations. The following parameters were recorded: age, sex, duration of SLE, photosensitivity, skin changes, active arthritis, LN, and history of drug intake [steroids, hydroxychloroquine, calcium, and VD supplements]. The following laboratory investigations performed include: urine analysis, erythrocyte sedimentation rate (ESR), Creactive protein (CRP), serum creatinine, ALT, C3, C4 concentrations, creatine phosphokinase (CPK), presence of anti-nuclear auto-antibodies (ANA) and the anti-dsDNA, 24-h protein in urine, and lipid profile including serum cholesterol, serum triglycerides, low-density lipoproteins, and high-density lipoproteins.

The assessment of SLE activity was determined according to the modified SLE disease activity index (SLEDAI) score with higher scores representing increased activity [15], while LN was assessed by renal SLEDAI [16].

In our study, SLE patients were classified as follows: (i) active SLE: SLEDAI score of 8 or more (82 patients), (ii) inactive SLE: SLEDAI score of less than 8 (18 patients), (iii) lupus nephritis patients (68 patients), (iv) SLE patients without nephritis (32 patients).

The sample size was determined in accordance with SLEDAI scores in both active SLE and LN. The calculated minimum sample size was 100 SLE patients.

\section{Assessment of vitamin D}

Serum 25-hydroxycholecalciferol VD (25(OH)D) was measured by using Abcam ELISA Kit catalog number ab213966. Insufficient VD was estimated at levels $<30 \mathrm{ng} /$ $\mathrm{mL}$ and deficiency at $<10 \mathrm{ng} / \mathrm{mL}$. We considered any level of $\mathrm{VD}<30 \mathrm{ng} / \mathrm{mL}$ a low value for statistical purposes.

\section{Statistical analysis}

Statistical analysis was done by utilizing statistical Package Social Sciences version 20.0 (SPSS). Continuous data were expressed as mean \pm standard deviation (SD), but categorical data were expressed in percentages and numbers. Differences between groups were determined using the chi-square test for categorical data or $T$ test for continuous data. Correlation between different variables was performed. The receiver operating characteristic (ROC) curve was performed for calculation of sensitivity, specificity, positive predictive value (PPV), negative predictive value (NPV), and accuracy. Statistical significance was defined as a $P$ value $<0.05$.

\section{Results}

In our current study, systemic lupus erythematosus group included 88 females (88\%) and 12 males (12\%), and their disease duration ranged from 0.5 to 12.0 years with a mean \pm SD of $4.0 \pm 3.2$ years. The 66 healthy 
controls included 58 females (87.87\%) and eight males (12.12\%), with mean age \pm SD of $25.32 \pm 6.98$ with a range of 18.0-51.0 years. There was no significant difference among the patients and the control group regarding age and sex (Table 1).

Comparing the laboratory findings between SLEDAI $\geq$ 8 and SLEDI $<8$ groups, our results revealed that SLEDAI $\geq 8$ group had significantly lower values of CPK (68.88 \pm 30.08$)(P=0.03), C 4(2.06 \pm 1.21)(P=0.000)$, and $25(\mathrm{OH}) \mathrm{VD}(3.00 \pm 2.27)(P=0.02)$ compared to SLEDAI $<8$ group (Table 2).

As for the comparison between renal SLEDAI groups, levels of CPK $(68.29 \pm 27.64)(P=0.02)$, serum albumin $(36.03 \pm 7.63)(P=0.04)$, and $25(\mathrm{OH}) \mathrm{VD}(\mathrm{ng} / \mathrm{ml})(2.58 \pm$ 1.82) (0.003) in positive renal SLEDAI group are significantly lower than in negative renal SLEDI group. A significant increase in the levels of ALP $(84.88 \pm 63.78)(P=$ $0.03)$ and 24-h urinary proteins $(\mathrm{mg})(1581.81 \pm 1886.05)$ $(P=0.003)$ was significantly higher in positive renal SLEDAI group versus negative renal SLEDAI group. None of the negative renal SLEDAI group had pus in the urine, hematuria mean while $64.7 \%$; $55.9 \%$ of the positive renal SLEDAI had pus in the urine and hematuria respectively (Table 3).

Table 1 Demographic and laboratory data of SLE patients and control group

\begin{tabular}{llll}
\hline Variables & SLE $(\boldsymbol{n}=100)$ & Control $(\boldsymbol{n}=66)$ & $\boldsymbol{P}$ value \\
\hline $\begin{array}{l}\text { Age (years) } \\
\quad \text { Mean } \pm \text { SD }\end{array}$ & $28.30 \pm 8.9$ & $25.32 \pm 6.98$ & 0.93 \\
$\quad$ Range & $(19.0-54.0)$ & $(18.0-51.0)$ & \\
Sex & & & \\
$\quad$ Male & $12(12 \%)$ & $8(12.12 \%)$ & 0.99 \\
$\quad$ Female & $88(88 \%)$ & $58(87.87)$ & 0.89 \\
Duration of disease & & & \\
$\quad$ Mean \pm SD & $4.0 \pm 3.2$ & & \\
$\quad$ Range & $(0.5-12.0)$ & & \\
ANA & & & $0.000^{*}$ \\
negative & $14(14 \%)$ & $66(100 \%)$ & \\
positive & $86(86 \%)$ & 0 & $0.000^{*}$ \\
Anti-dsDNA & $2.00 \pm 1.57$ & $0.25 \pm 0.12$ & $0.000^{*}$ \\
C3 (ug/ml) & $3.39 \pm 2.92$ & $7.06 \pm 3.36$ & $0.000^{*}$ \\
C4 (ug/ml) & $2.48 \pm 1.61$ & $4.73 \pm 2.34$ & $0.002^{* *}$ \\
25(OH)D (ng/ml) & $3.38 \pm 2.55$ & $5.36 \pm 2.88$ & \\
\hline Da a & & & \\
\end{tabular}

Data are presented as mean \pm SD (standard deviation) or number ( $n)$ and percentage (\%). The independent samples $t$ test was used to compare between means of different parameters in SLE patients and controls. Chisquare test was used to analyze the significance between the percentages. $P$ value $<0.05$ is considered to be a significant value ANA anti-nuclear auto-antibodies, Anti dsDNA anti-double strand antibody, C3 complement 3, C4 complement 4, 25(OH)D 25-hydroxyvitamin D

*Statistically significant $(P<0.05)$

**Moderately statistically significant $(P<0.01)$
Interestingly, we found no significant differences in 25(OH)VD levels between patients taking hydroxychloroquine and those not, where $25(\mathrm{OH}) \mathrm{VD}$ levels were 3.41 $\pm 2.63 \mathrm{ng} / \mathrm{ml}$ in patients taking hydroxychloroquine and $3.13 \pm 2.11 \mathrm{ng} / \mathrm{ml}$ in those who were hydroxychloroquine free. In addition, we found that serum 25(OH)VD levels were not significantly different among patients taking steroids $(3.51 \pm 2.73 \mathrm{ng} / \mathrm{ml})$ and those who were steroid-free $(2.65 \pm 1.19 \mathrm{ng} / \mathrm{ml})$ (Table 4).

In our current study, significant negative correlations between levels of serum 25(OH)VD and clinical findings in studied SLE patients, including mucocutaneous, malar rash, and renal symptoms, also, there was significant negative correlation between 25(OH)VD level and both SLEDAI and renal SLEDAI scores. Importantly, serum 25(OH)VD showed no significant correlation with C3, $\mathrm{C} 4$, serum creatinine, and other clinical and lab results in SLE patients (Table 5).

Multiple logistic regression analysis showed that the most potent parameters determining low levels of serum $25(\mathrm{OH}) \mathrm{VD}$ were higher SLEDAI score $(p=0.002)$ and lower C3 $(p=0.035)$ (Table 6).

To quantify the utility of $25(\mathrm{OH}) \mathrm{VD}$ in determining the activity in SLE patients, analysis by ROC curve of $25(\mathrm{OH}) \mathrm{VD}$ for SLEDAI and renal SLEDAI is shown in Fig. 1, where the sensitivity and specificity were $73.2 \%$ and $77.8 \%$, respectively; positive predictive value (PPV) and negative predictive value (NPV) were $93.7 \%$ and $38.9 \%$, respectively; and $74.0 \%$ accuracy at cutoff point < 2.5 with an area under curve (AUC) 0.748. Besides, our study also showed that $25(\mathrm{OH}) \mathrm{VD}$ at cutoff point $<2.2$ $\mathrm{ng} / \mathrm{ml}$ had a sensitivity and specificity of $64.7 \%$ and 93.8\% respectively, PPV and NPV are $95.7 \%$ and 55.6\% respectively, and $74.0 \%$ accuracy (Fig. 1 ).

\section{Discussion}

Measurement of circulating $25(\mathrm{OH}) \mathrm{VD}$ is considered the best indicator of VD status in humans, as it represents VD stores gained from both dietary intake and ultraviolet light [17]. Despite the certainty of the presence of sunny days most of the year in Egypt, the present study proposes that VD deficiency is widely predominant in patients with active SLE and LN in Egypt, this is in accordance with Elsaid et al. who found that the prevalence of VD deficiency and insufficiency in LN patients is as high as $93.4 \%$ in Egyptian patients [18]. Our study results also were in agreement with Korah et al. who found that Egyptian SLE patients had lower VD levels in comparison to healthy controls [19]. Additionally, our study showed that low VD levels could act as an independent risk factor for SLE activity where the mean concentration of VD was significantly lower in SLEDAI score $\geq 8(3.00 \pm 2.27 \mathrm{ng} / \mathrm{ml})$ versus in SLEDAI score < $8(5.10 \pm 3.19 \mathrm{ng} / \mathrm{ml})$. These findings documented low 
Table 2 Comparison between SLEDAl groups regarding the laboratory tests

\begin{tabular}{|c|c|c|c|}
\hline Variable & SLEDAI $<8 " \boldsymbol{n}=18 "$ & SLEDAI $\geq 8$ " $\boldsymbol{n}=82^{\prime \prime}$ & $\boldsymbol{P}$ value \\
\hline ESR (mm/1st h) & $40 \pm 29.82$ & $49.54 \pm 30.97$ & 0.93 \\
\hline CRP (mg/L) & $9.02 \pm 15.71$ & $11.21 \pm 18.56$ & 0.83 \\
\hline $\mathrm{Hb}(\mathrm{g} / \mathrm{dl})$ & $11.22 \pm 1.16$ & $10.87 \pm 1.63$ & 0.55 \\
\hline $\operatorname{RBCs}\left(10^{3} / \mu \mathrm{l}\right)$ & $3.90 \pm 0.90$ & $4.27 \pm 0.69$ & 0.18 \\
\hline WBCs $\left(10^{3} / \mu \mathrm{l}\right)$ & $5.30 \pm 2.42$ & $5.26 \pm 2.35$ & 0.96 \\
\hline Platelets $\left(10^{3} / \mu \mathrm{l}\right)$ & $286.33 \pm 100.18$ & $280.34 \pm 114.63$ & 0.88 \\
\hline AST (U/L) & $22.56 \pm 9.40$ & $23.92 \pm 8.79$ & 0.83 \\
\hline ALT (U/L) & $25.11 \pm 16.51$ & $19.44 \pm 3.47$ & 0.47 \\
\hline ALP (IU/L) & $87.33 \pm 15.85$ & $73.59 \pm 53.79$ & 0.50 \\
\hline CPK (U/L) & $133.89 \pm 64.09$ & $68.88 \pm 30.08$ & $0.03^{*}$ \\
\hline LDH (U/L) & $289.44 \pm 94.65$ & $321.39 \pm 136.55$ & 0.51 \\
\hline Serum albumin (g/dl) & $40.12 \pm 4.01$ & $37.50 \pm 7.85$ & 0.34 \\
\hline A/G ratio & $1.24 \pm 0.311$ & $1.16 \pm 0.35$ & 0.53 \\
\hline Glucose (mmol/L) & $4.88 \pm 1.13$ & $5.71 \pm 1.02$ & 0.71 \\
\hline Urea (mmol/L) & $4.20 \pm 1.36$ & $6.15 \pm 0.73$ & 0.23 \\
\hline Creatinine $(\mu \mathrm{mol} / \mathrm{L})$ & $49.80 \pm 14.34$ & $80.66 \pm 20.29$ & 0.48 \\
\hline Serum TC(mg/dl) & $151.55 \pm 31.33$ & $172.12 \pm 46.56$ & 0.21 \\
\hline serum TG(mg/dl) & $109.00 \pm 46.48$ & $140.39 \pm 17.40$ & 0.48 \\
\hline HDL-c (mg/dl) & $40.97 \pm 7.45$ & $45.64 \pm 17.03$ & 0.43 \\
\hline LDL-c (mg/dl) & $88.11 \pm 23.08$ & $98.11 \pm 42.79$ & 0.50 \\
\hline Creatinine Clearance $(\mathrm{ml} / \mathrm{min})$ & $86.24 \pm 38.95$ & $103.43 \pm 45.41$ & 0.30 \\
\hline $24 \mathrm{~h}$ protein in urine $(\mathrm{mg})$ & $723.04 \pm 272.82$ & $1275.0 \pm 278.89$ & 0.37 \\
\hline \multicolumn{4}{|l|}{ Pus/HPF in urine } \\
\hline negative & $7(77.8 \%)$ & $21(51.2 \%)$ & 0.14 \\
\hline positive & $2(22.2 \%)$ & 20(48.8\%) & \\
\hline \multicolumn{4}{|l|}{$\mathrm{RBCs}$ in urine } \\
\hline negative & $7(77.8 \%)$ & $24(58.5 \%)$ & 0.25 \\
\hline positive & $2(22.2 \%)$ & $17(41.5 \%)$ & \\
\hline \multicolumn{4}{|l|}{ Urinary cast } \\
\hline negative & $8(88.9 \%)$ & $37(90.2 \%)$ & 0.65 \\
\hline positive & $1(11.1 \%)$ & $4(9.8 \%)$ & \\
\hline \multicolumn{4}{|l|}{ Crystals in urine } \\
\hline negative & $7(77.8 \%)$ & $36(87.8 \%)$ & 0.37 \\
\hline positive & $2(22.2 \%)$ & $5(12.2 \%)$ & \\
\hline \multicolumn{4}{|l|}{ Albumin in urine } \\
\hline negative & $6(66.7 \%)$ & $23(56.1 \%)$ & 0.42 \\
\hline positive & $3(33.3 \%)$ & $18(43.9 \%)$ & \\
\hline C3 $(\mu \mathrm{g} / \mathrm{ml})$ & $4.77 \pm 2.16$ & $3.09 \pm 2.36$ & 0.119 \\
\hline $\mathrm{C} 4(\mu \mathrm{g} / \mathrm{ml})$ & $4.40 \pm 1.88$ & $2.06 \pm 1.21$ & $0.000^{* * *}$ \\
\hline Anti-dsDNA & $1.34 \pm 1.20$ & $2.14 \pm 1.62$ & 0.170 \\
\hline 25(OH)D (ng/ml) & $5.10 \pm 3.19$ & $3.00 \pm 2.27$ & $0.02^{*}$ \\
\hline
\end{tabular}

Data are presented as numbers $(n)$ and mean \pm SD (standard deviation). The independent samples $t$ test was used to compare between means of different parameters in SLEDAI groups. $P$ value $<0.05$ is considered to be a significant value

SLEDAl systemic lupus erythematosus disease activity index, ESR erythrocyte sedimentation rate, CRP C- reactive protein, $H b$ hemoglobin, $R B C s$ red blood cells, WBCs white blood cells, AST aspartate transaminase, ALT alanine transaminase, ALP alkaline phosphatase, CPK creatinine phosphokinase, $L D H$ lactate dehydrogenase, $A / G$ ratio albumin globulin ratio, $T C$ total cholesterol, $T G$ triglyceride, $H D L$ high-density lipoproteins, $L D L$ low-density lipoproteins, $H P F$ high power field, C3 complement 3, C4 complement 4, Anti-dsDNA anti-d double-stranded deoxyribonucleic acid, 25(OH)D 25 hydroxyvitamin D *Statistically significant $(P<0.05)$

***Highly statistically significant $(P<0.001)$ 
Table 3 Comparison between renal SLEDAI groups regarding the laboratory tests

\begin{tabular}{|c|c|c|c|}
\hline Variable & Renal SLEDAI (negative) " $\boldsymbol{n}=32$ " & Renal SLEDAI (positive) "n=68" & $\boldsymbol{P}$ value \\
\hline AST (U/L) & $21.56 \pm 9.05$ & $24.67 \pm 20.23$ & 0.43 \\
\hline ALT (U/L) & $18.75 \pm 12.57$ & $21.26 \pm 24.50$ & 0.4 \\
\hline ALP (IU/L) & $57.31 \pm 14.79$ & $84.88 \pm 63.78$ & $0.03^{*}$ \\
\hline CPK (U/L) & $106.69 \pm 146.50$ & $68.29 \pm 27.64$ & $0.02^{*}$ \\
\hline LDH (U/L) & $286.69 \pm 71.40$ & $329.26 \pm 148.62$ & 0.09 \\
\hline Serum albumin $(g / d l)$ & $42.13 \pm 4.61$ & $36.03 \pm 7.63$ & $0.04^{*}$ \\
\hline A/G ratio & $1.32 \pm 0.39$ & $1.11 \pm 0.30$ & 0.42 \\
\hline Glucose (mmol/L) & $5.08 \pm 1.57$ & $5.80 \pm 7.14$ & 0.4 \\
\hline Urea (mmol/L) & $4.69 \pm 1.88$ & $6.32 \pm 5.04$ & 0.08 \\
\hline Creatinine $(\mu \mathrm{mol} / \mathrm{L})$ & $48.4 \pm 16.08$ & $87.68 \pm 141.82$ & 0.15 \\
\hline Serum total cholesterol (mg/dl) & $167.25 \pm 35.43$ & $168.97 \pm 48.88$ & 0.41 \\
\hline Triglyceride (mg/dl) & $136.06 \pm 131.44$ & $134.12 \pm 89.17$ & 0.89 \\
\hline HDL-C (mg/dl) & $47.85 \pm 14.31$ & $43.38 \pm 16.44$ & 0.48 \\
\hline $\mathrm{LDL}-\mathrm{C}(\mathrm{mg} / \mathrm{dl})$ & $90.11 \pm 40.73$ & $99.24 \pm 39.87$ & 0.97 \\
\hline Creatinine Clearance (ml/min) & $93.97 \pm 40.15$ & $103.33 \pm 46.61$ & 0.87 \\
\hline $24 \mathrm{~h}$ protein in urine $(\mathrm{mg})$ & $312.43 \pm 129.10$ & $1581.81 \pm 1886.05$ & $0.003^{* *}$ \\
\hline Pus/HPF in urine & & & $0.002^{* *}$ \\
\hline negative & $16(100 \%)$ & $12(35.3 \%)$ & \\
\hline positive & $0(0 \%)$ & $22(64.7 \%)$ & \\
\hline
\end{tabular}

RBCs in urine

$\begin{array}{lll}\text { negative } & 16(100 \%) & 15(44.1 \%) \\ \text { positive } & 0(0 \%) & 19(55.9 \%)\end{array}$

Urinary cast

negative

positive

Crystals in urine

$\begin{array}{lll}\text { negative } & 15(93.8 \%) & 28(82.4 \%) \\ \text { positive } & 1(6.2 \%) & 6(17.6 \%)\end{array}$

Albumin in urine

positive

C3 $(\mu \mathrm{g} / \mathrm{ml})$

$3.05 \pm 2.22$

$3.23 \pm 3.06$

Data are presented as mean \pm SD. The independent samples $t$ test was used to compare between means of different parameters in SLEDAI groups. $P$ value $<0.05$ is considered to be a significant value

SD standard deviation, SLEDAl systemic lupus erythematosus disease activity index, $A S T$ aspartate transaminase, $A L T$ alanine transaminase, $A L P$ alkaline phosphatase, $C P K$ creatinine phosphokinase, $L D H$ lactate dehydrogenase, $A / G$ ratio albumin globulin ratio, $T C$ total cholesterol, $T G$ triglyceride, $H D L-C$ high-density lipoprotein cholesterol, LDL-C low-density lipoprotein cholesterol, HPF high power field, C3 complement 3, C4 complement 4, Anti-dsDNA anti-d double-stranded deoxyribonucleic acid, 25(OH)D 25 hydroxyvitamin D

* Statistically significant $(P<0.05)$

**Moderately statistically significant $(P<0.01)$

***Highly statistically significant $(P<0.001)$ 
Table 4 Comparison between steroids, hydroxychloroquine, calcium, and VD supplements with anti-ds DNA and 25(OH)D

\begin{tabular}{|c|c|c|c|c|c|c|c|c|c|}
\hline & $\begin{array}{l}\mathrm{HQ} \\
\text { (negative) } \\
" \boldsymbol{n}=12^{\prime \prime}\end{array}$ & $\begin{array}{l}\text { HQ } \\
\text { (positive) } \\
\text { "n = 88" }\end{array}$ & $\boldsymbol{P}$ value & $\begin{array}{l}\text { Steroids } \\
\text { (negative) } \\
" \boldsymbol{n}=16 "\end{array}$ & $\begin{array}{l}\text { Steroids } \\
\text { (positive) } \\
\text { " } \boldsymbol{n}=84 "\end{array}$ & $\boldsymbol{P}$ value & $\begin{array}{l}\text { Calcium and VD } \\
\text { (negative) } \\
\text { " } \boldsymbol{n}=74 "\end{array}$ & $\begin{array}{l}\text { Calcium and VD } \\
\text { (positive) } \\
\text { " } \boldsymbol{n}=26 "\end{array}$ & $\boldsymbol{P}$ value \\
\hline Anti-dsDNA & $2.71 \pm 1.28$ & $1.90 \pm 0.99$ & 0.24 & $2.37 \pm 1.98$ & $1.93 \pm 1.19$ & 0.24 & $2.12 \pm 1.68$ & $1.63 \pm 1.23$ & 0.34 \\
\hline $25(\mathrm{OH}) \mathrm{D}$ & $3.13 \pm 2.11$ & $3.41 \pm 2.63$ & 0.80 & $2.65 \pm 1.19$ & $3.51 \pm 2.73$ & 0.97 & $2.13 \pm 1.04$ & $6.92 \pm 2.25$ & $0.000^{* * *}$ \\
\hline
\end{tabular}

Data are presented as mean \pm SD. The independent samples $t$ test was used to compare between means of different parameters. $P$ value $<0.05$ is considered to be a significant value

$H Q$ hydroquine, Anti-dsDNA anti-d double stranded deoxyribonucleic acid, 25(OH)D 25 hydroxyvitamin D

***Highly statistically significant $(P<0.001)$

VD levels among Egyptian individuals especially in SLE patients despite the effect of high-ultraviolet seasons most of the year which could be explained by conventional clothing that frequently decreases their exposure to the sun [20].

There is conflicting evidence regarding the effect of chronic use of corticosteroids on VD metabolism [21]. A previous study showed that corticosteroid intake was inversely associated with serum 25(OH)D3 [22]. On the contrary, our study found no significant differences in 25(OH)VD levels between patients taking corticosteroids and those who were not taking corticosteroids; this finding was in agreement with Mazziotti et al.'s results that explained this finding by the fact that usage of low-dose of corticosteroids (10 mg/d prednisolone equivalent) have no effect on VD levels [23].

As for the effect of antimalarial drug on VD level, our study did not show a significant difference in serum 25(OH)D3 level between those who take anti-malarial treatment and those who do not. It is well-known that hydroxychloroquine is considered an important drug in SLE management; however, it was suspected to decrease the conversion of $25(\mathrm{OH}) \mathrm{D} 3$ to more biologically active $1,25(\mathrm{OH}) 2 \mathrm{D} 3$ [22]. In agreement with our results, recent studies found that serum 25(OH)D3 levels in SLE patients are not altered by taking hydroxychloroquine [24, 25]. Still, further studies are needed as the majority of our patients are taking antimalarial treatment.

Our study showed that VD supplementation is comparatively safe and significantly increases the levels of serum 25(OH)VD in patients with SLE, even though, VD supplements do not appear to significantly decrease the positivity of anti-dsDNA and SLE activity (Table 4), this is in agreement with Zheng et al. [26]. Another interesting observation in our study is the inverse correlation between serum levels of VD and clinical symptoms in SLE patients including mucocutaneous, malar rash, and renal symptoms. However, our study showed no correlation between VD levels and fatigue in SLE patients; our finding is consistent with Fragoso et al. who also revealed no significant association between VD levels and fatigue in SLE patients [10], but our observation was different from that of Stockton et al., who observed a significant correlation between fatigue and VD levels in SLE [27]. This discrepancy could be explained as blood VD levels do not indicate the amount of VD stored in body tissues [28]. Moreover, recent reviews discussed the association between serum VD levels and clinical data in SLE patients including fatigue and documented the presence of several controversies regarding the association of VD levels and fatigue $[9,29]$.

There are variable interesting observations in the present study that suggest the presence of a serious function for vitamin D3 in disease modulation. Our results revealed that serum VD level had a significant negative correlation with SLEDAI score in both active SLE and LN. This could be explained by the potential role of vitamin $\mathrm{D}$ in the immune system [30]. It was proposed that immune cells as $\mathrm{T}$ cells, $\mathrm{B}$ cells, dendritic cells, and macrophages, which express VD receptors, can be promoted by adequate VD supplements. Additionally, several autoimmune disorders are associated with low VD levels [7]. In agreement with our results, various past studies showed a potent negative correlation between SLEDAI score and VD levels [18, 31, 32]. Moreover, systemic lupus erythematosus patients with severe VD deficiency were found to have significantly more SLE flares and nephritis [33]. This observed significant negative correlation between SLE activity and VD level in our study could be predicted as VD catabolic process is enhanced by the underlying inflammation in lupus [34]. Still the association between VD level and SLEDAI scores has not been uniform across observations where several studies have found none [35, 36].

Another interesting observation in the current study is the absence of correlation between 25(OH)VD with laboratory investigation including, $\mathrm{C} 3(r=-0.153, P=0.288), \mathrm{C} 4(r=$ $0.177, P=0.22)$, and anti-dsDNA $(r=-0.136, P=0.345)$; these findings were matched with those of Mok et al. [37]. In disagreement with our study, Mandal et al. found that the plasma level of 25-OH VD was negatively correlated with anti-dsDNA $(r=-0.39, P<0.0001)$ [38]; also, Bonakdar et al. and Nerviani et al. found a significant correlation between VD deficiencies with anti-dsDNA, lower serum 
Table 5 25(OH)VD correlations with clinical data, laboratory investigations, SLEDAl, renal SLEDAl, and immunological parameters

\begin{tabular}{|c|c|c|}
\hline Variable & $25(\mathrm{OH}) \mathrm{D} \boldsymbol{r}$ value & 25(OH)D $\boldsymbol{P}$ value \\
\hline Fatigue & 0.002 & 0.99 \\
\hline Fever & -0.131 & 0.28 \\
\hline Mucocutaneous & -0.234 & $0.05^{*}$ \\
\hline Alopecia & -0.189 & 0.12 \\
\hline Malar rash & -0.287 & $0.02^{*}$ \\
\hline Ulcer & -0.082 & 0.50 \\
\hline Musculoskeletal & 0.8 & 0.50 \\
\hline Myositis & 0.92 & 0.44 \\
\hline Arthritis & -0.016 & 0.89 \\
\hline Neuropsychiatric & -0.082 & 0.50 \\
\hline Vasculitis & -0.078 & 0.52 \\
\hline Renal & -0.43 & $0.000^{* * *}$ \\
\hline Serositis & -0.168 & 0.16 \\
\hline ESR & -0.144 & 0.31 \\
\hline CRP & -0.088 & 0.54 \\
\hline HB & 0.141 & 0.32 \\
\hline RBCs & -0.050 & 0.72 \\
\hline WBCs & -0.064 & 0.65 \\
\hline PLT & 0.095 & 0.51 \\
\hline ALT & -0.004 & 0.97 \\
\hline AST & 0.014 & 0.92 \\
\hline ALP & -0.061 & 0.67 \\
\hline CPK & 0.114 & 0.43 \\
\hline LDH & -0.196 & 0.17 \\
\hline Serum albumin & 0.189 & 0.19 \\
\hline $\mathrm{A} / \mathrm{G}$ ratio & 0.198 & 0.17 \\
\hline Glucose & -0.105 & 0.47 \\
\hline Urea & -0.199 & 0.17 \\
\hline Creatinine & -0.123 & 0.4 \\
\hline Cholesterol & -0.117 & 0.42 \\
\hline Triglyceride & -0.049 & 0.74 \\
\hline HDL & -0.056 & 0.7 \\
\hline LDL & -0.094 & 0.52 \\
\hline Creatinine clearance & -0.065 & 0.65 \\
\hline $24 \mathrm{~h}$ protein in urine & -0.170 & 0.24 \\
\hline SUA & -0.199 & 0.17 \\
\hline ANA & 0.142 & 0.24 \\
\hline SLEDAI & -0.361 & $0.01^{*}$ \\
\hline Renal SLEDAI & -0.325 & $0.02^{*}$ \\
\hline C3 & -0.153 & 0.288 \\
\hline C4 & 0.177 & 0.22 \\
\hline Anti-dsDNA & -0.136 & 0.345 \\
\hline
\end{tabular}

Data shown are Pearson's correlation coefficient $(r)$ and $p$ values. Significant correlations are highlighted in bold letters and shown as $P$ value $<0.05$ is a significant value

** Statistically significant $(P<0.05)$

***Highly statistically significant $(P<0.001)$
Table 6 Multiple regression analysis to assess the most affected parameters with 25(OH)VD deficiency

\begin{tabular}{lll}
\hline Variable & Beta & $\boldsymbol{P}$ value \\
\hline SLEDAI score & -0.455 & $\mathbf{0 . 0 0 2 ^ { * * }}$ \\
C3 & -0.297 & $\mathbf{0 . 0 3 5}^{\text {** }}$
\end{tabular}

$P$ value $<0.05$ is considered to be a significant value

SLEDAI systemic lupus erythematosus disease activity index, C3 complement 3

**Moderately statistically significant

albumin, higher levels of liver enzymes, and higher hemoglobin concentrations [39, 40]. This controversy could be attributed to the immunosuppressive effect of the corticosteroids taken by $84 \%$ of our patients.

The present study showed no significant association between VD levels with ESR and CRP; this is in agreement with several studies that also did not find this association $[5,25]$.

In the current study, we performed multiple regression analyses to explore the clinical or laboratory manifestations with the strongest association with the serum VD levels among SLE patients. Multiple regression analysis showed that the SLEDAI score and C3 complement are potent predictors for lower serum 25(OH)VD levels. In disagreement with several studies [19], our study showed no significant association between lab parameters as proteinuria and creatinine level with lower serum VD level in the regression analysis, but the value of this finding is diminished by the fact that the mean \pm SD of serum creatinine in the SLEDAI scores in both active SLE and LN was $80.66 \pm 20.29$ and $87.68 \pm 141.82$, respectively. Our results showed that VD had a sensitivity and specificity of $73.2 \%$ and $77.8 \%$, respectively, for determining SLE activity at cutoff point $<2.5$ and at cutoff point $<2.2$; the sensitivity and specificity were $64.7 \%$ and $93.8 \%$ respectively for determining LN; these results are in concordance with Mok et al. results [37].

Few restrictions of this study involve the small number of patients and our inability to obtain enough renal tissue from all SLE patients for histopathology, either due to contraindicated active LN thrombocytopenia or refusal of patients, so studying a larger number of populations with variable treatment protocols to confirm the association between VD with SLE activity and nephritis is recommended to confirm the findings of the present study.

\section{Summary}

The major results of the present study can be summarized in the following points: (I) Low serum VD level is an independent risk factor in active SLE those with LN. (II) Low VD level is associated with mucocutaneous, malar rash, and renal symptoms. (III) VD is inversely correlated with SLEDI and renal SLEDI scores. 


\section{A) ROC curve of $25(\mathrm{OH})$ VD for SLEDAI with AUC 0.748:}

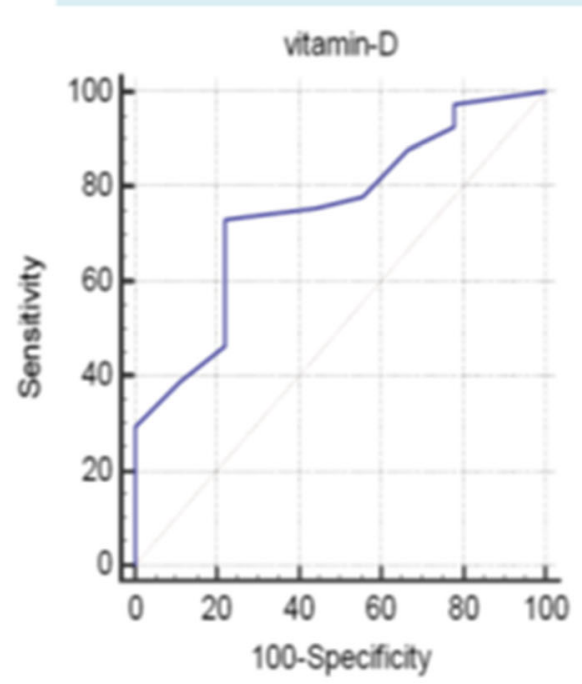

B) ROC curre of 25(OH) VD for renal SLEDAI with AUC 0.814:

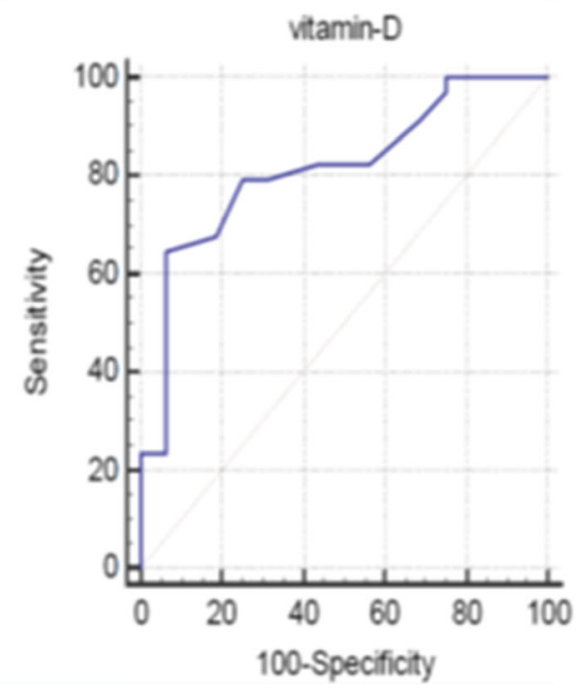

Fig. 1 ROC curve of 25(OH)D for SLEDAI with AUC 0.748 and renal SLEDAI with AUC 0.814

\section{Conclusion}

Vitamin D deficiency is common in patients with SLE especially in LN and in SLE with SLEDAI score $\geq 8$ patients. Low serum VD is significantly associated with higher SLEDAI and renal SLEDAI scores. The presence of mucocutaneous, malar rash, and renal symptoms are significantly correlated with VD deficiency. Higher SLEDAI scores and lower $\mathrm{C} 3$ are the strongest predictors of low serum VD levels among SLE patients. Finally, adding VD level as a marker to routine follow-up may result in earlier diagnosis of SLE activity and LN in adult SLE patients.

\section{Abbreviations}

ALT: Alanine aminotransferase; ANA: Anti-nuclear auto-antibodies; AntiDNA: Anti-double strand antibody; AST: Aspartate transaminase;

C3: Complement 3; C4: Complement 4; CPK: Creatine phosphokinase; CRP: Creactive protein; ESR: Erythrocyte sedimentation rate; $\mathrm{Hb}$ : Hemoglobin; HDL: High-density lipoproteins; LDH: Lactate dehydrogenase; ROC: Receiver operating characteristic curve; SD: Standard deviation; SLE: Systemic lupus erythematosus; SLEDAl: Systemic lupus erythematosus disease activity index; SLICC: Systemic Lupus International Collaborating Clinics classification criteria; VD: Vitamin D; VDRs: VD receptors; (25(OH)D): 25-hydroxycholecalciferol

\section{Acknowledgements}

I would like to express my deepest gratitude for all my co-authors and all my participants who were the cornerstone for the achievements in this research article to appear.

\section{Authors' contributions}

MKK and YSM conceived of the presented idea. MKK, YSM, and MAD developed the theory and performed the computations. MKK, YSM, and MAD verified the analytical methods. MKK, YSM, and MAD revised all the findings of this work. All authors discussed the results and contributed to the final manuscript. MKK and YSM carried out the experiment. MKK wrote the manuscript with support from MAD. MKK and MAD contributed to sample preparation. MKK and MAD contributed to the interpretation of the results. All authors provided critical feedback and helped shape the research, analysis, and manuscript. All authors approved the submitted version. All authors agreed to be personally accountable for the author's own contributions and to ensure that questions related to the accuracy or integrity of any part of the work, even ones in which the author was not personally involved, are appropriately investigated, resolved, and the resolution documented in the literature. All authors have read and approved the manuscript.

\section{Funding}

Authors declare that they did not receive any funding to do this work.

\section{Availability of data and materials}

The data that support the findings of this study are available from the corresponding author upon reasonable request.

Ethics approval and consent to participate

There was no risk during the application of the research. Privacy and confidentiality was maintained during all stages of assessment. Every patient subjected to this study was informed about the results of the research.

This study was approved by the ethics committee of Faculty of Medicine, Assiut University, with approval number 17300432.

The study protocol was reviewed and approved by Medical Ethics

Committee in accordance with Helsinki declaration.

Consent to participate statement:

Consent (written) was obtained from the patient to participate in this study. Refusal would not affect medical services which are usually offered.

\section{Consent for publication}

Consent for publication (written) was obtained from all the participating patients. Written consent is approved by the ethics committee.

\section{Competing interests}

The authors declare that they have no competing interests.

\section{Author details}

${ }^{1}$ Nephrology Unit, Internal Medicine Department, Faculty of Medicine, Assiut University Hospital, Assiut University, Assiut, Egypt. ${ }^{2}$ Department of Rheumatology and Rehabilitation, Faculty of Medicine, Assiut University, 
Assiut, Egypt. ${ }^{3}$ Department of Medical Biochemistry and molecular Biology, Faculty of Medicine, Assiut University, Assiut, Egypt.

\section{Received: 15 June 2020 Accepted: 14 August 2020} Published online: 20 October 2020

\section{References}

1. Aringer M, Costenbader K, Daikh D, Brinks R, Mosca M, Ramsey-Goldman R et al (2019) 2019 European league against rheumatism/American College of Rheumatology classification criteria for systemic lupus erythematosus. Arthritis Rheumatol 71(9):1400-1412

2. Liu D, Fang $Y X$, Wu $X$, Tan W, Zhou W, Zhang $Y$ et al (2019) 1, 25-(OH) 2 D3/vitamin $D$ receptor alleviates systemic lupus erythematosus by downregulating Skp2 and upregulating p27. Cell Commun Signal 17(1):163

3. Liu, T., Son, M., \& Diamond, B. (2020). HMGB1 in systemic lupus erythematosus. Front Immunol, 11. 2020; Accessed: March 11, 2020.

4. Bikle DD (2014) Vitamin D metabolism, mechanism of action, and clinical applications. Chem Biol 21(3):319

5. Miskovic R, Plavsic A, Raskovic S, Jovicic Z et al (2015) Vitamin D status in patients with systemic lupus erythematosus in Serbia: correlation with disease activity and clinical manifestations. Open Access Maced J Med Sci 3(2):256

6. Hassanalilou T, Khalili L, Ghavamzadeh S, Shokri A, Payahoo L, Bishak YK (2018) Role of vitamin D deficiency in systemic lupus erythematosus incidence and aggravation. Auto Immun Highlights 9(1):1

7. Murdaca G, Tonacci A, Negrini S, Greco M, Borro M, Puppo F et al (2019) Emerging role of vitamin D in autoimmune diseases: an update on evidence and therapeutic implications. Autoimmun Rev 18(9):102350

8. Schröder-Heurich B, Springer CJP et al (2020) Vitamin D effects on the immune system from periconception through pregnancy. Nutrients 12(5): 1432

9. Nguyen MH, Bryant K, O'Neill SG (2018) Vitamin D in SLE: a role in pathogenesis and fatigue? A review of the literature. Lupus 27(13):20032011. https://doi.org/10.1177/0961203318796293

10. Fragoso TS, Dantas AT, Marques CD, Rocha Junior LF, Melo JH et al (2012) 25-Hydroxyivitamin D3 levels in patients with systemic lupus erythematosus and its association with clinical parameters and laboratory tests. Rev Bras Reumatol 52:60-65

11. Almaani S, Meara A, Rovin BH (2017) Update on lupus nephritis. Clin J Am Soc Nephrol 12(5):825-835

12. Lateef A, Petri M (2012) Unmet medical needs in systemic lupus erythematosus. Arthritis Res Therapy 14(S4):S4

13. Franca Gois, P. H., Wolley, M., Ranganathan, D.,.. \& Seguro, A. C. (2018). Vitamin $D$ deficiency in chronic kidney disease: recent evidence and controversies. Int J Environ Res Public Health, 15(8), 1773 D

14. Petri M, Orbai AM, Alarcón GS, Gordon C, Merrill JT, Fortin PR et al (2012) Derivation and validation of the systemic lupus international collaborating clinics classification criteria for systemic lupus erythematosus. Arthritis Rheumatism 64(8):2677-2686

15. Gladman DD, Ibanez D, Urowitz MB (2002) Systemic lupus erythematosus disease activity index 2000. J Rheumatol 29(2):288-291

16. Xuejing $Z$, Jiazhen $T$, Jun $L$, Xiangqing $X$, Shuguang Y, Fuyou L (2012) Urinary TWEAK level as a marker of lupus nephritis activity in 46 cases. J Biomed Biotechnol 2012

17. Pilz S, Zittermann A, Trummer C, Theiler-Schwetz V, Lerchbaum E, Keppel $\mathrm{MH}$ et al (2019) Vitamin D testing and treatment: a narrative review of current evidence. Endocrine Connect 8(2):R27-R43

18. Elsaid TO, Basma A, Nabih AA, Elewa AM (2018) Serum vitamin D in Egyptian patients with systemic lupus erythematous and its association with lupus nephritis. Int J Clin Rheumatol 13(5)

19. Korah TE, Soliman SG, Al-Sharaki DR et al (2013) Vitamin D in systemic lupus erythematosus patients with and without nephropathy. Egypt Rheumatol Rehabil 40(3):165-175

20. Mostafa WZ, Hegazy RA (2015) Vitamin D and the skin: focus on a complex relationship: a review. J Adv Res 6(6):793-804

21. Davidson ZE, Walker KZ, Truby H (2012) Do glucocorticosteroids alter vitamin D status? A systematic review with meta-analyses of observational studies. J Clin Endocrinol Metabol 97(3):738-744

22. Ruiz-Irastorza G, Egurbide MV, Olivares N, Martinez-Berriotxoa A, Aguirre C (2008) Vitamin D deficiency in systemic lupus erythematosus: prevalence, predictors and clinical consequences. Rheumatology 47(6):920-923
23. Mazziotti G, Formenti AM, Frara S, Doga M, Giustina A (2018) Vitamin D and Glucocorticoid-Induced Osteoporosis. In: Giustina A, Bilezikian JP (ed) Vitamin D in Clinical Medicine. Basel: Karger; Front Horm Res 50:149-60. https://doi.org/10.1159/000486078

24. Durcan L, Clarke WA, Magder LS, Petri M (2015) Hydroxychloroquine blood levels in systemic lupus erythematosus: clarifying dosing controversies and improving adherence. J Rheumatol 42(11):2092-2097

25. Kim HA, Sung JM, Jeon JY, Yoon JM, Suh CH (2011) Vitamin D may not be a good marker of disease activity in Korean patients with systemic lupus erythematosus. Rheumatol Int 31(9):1189-1194

26. Zheng R, Gonzalez A, Yue J, Wu X, Qiu M, Gui L et al (2019) Efficacy and safety of vitamin $D$ supplementation in patients with systemic lupus erythematosus: a meta-analysis of randomized controlled trials. Am J Med Sci 358(2):104-114onghao

27. Sockton KA, Kandiah DA, Paratz JD, Bennell KL (2012) Fatigue, muscle strength and vitamin D status in women with systemic lupus erythematosus compared with healthy controls. Lupus 21(3):271-278

28. De la Puente Yagüe M, Collado Yurrita L, Cuadrado Cenzual MA (2020) Role of vitamin $D$ in athletes and their performance: current concepts and new trends. Nutrients 12(2):579

29. Magro R, Borg AA (2017) The effect of vitamin D on disease activity, fatigue and interferon signature gene expression in systemic lupus erythematosus. Mediterr J Rheumatol 28(3):12

30. Chaiamnuay S, Chailurkit LO, Narongroeknawin P, Asavatanabodee $P$, Laohajaroensombat S, Chaiamnuay P (2013) Current daily glucocorticoid use and serum creatinine levels are associated with lower $25(\mathrm{OH})$ vitamin D levels in Thai patients with systemic lupus erythematosus. JCR: Journal of Clinical Rheumatology 19(3):121-112

31. Abaza NM, El-Mallah RM, Shaaban A, Mobasher SA, Al-Hassanein KF, Zaher AAA, El-Kabarity RH (2016) Vitamin D deficiency in Egyptian systemic lupus erythematosus patients: how prevalent and does it impact disease activity? Integrative medicine insights, 11, IMI-S40035

32. Lin TC, Wu JY, Kuo ML, Ou LS, Yeh KW, Huang JL (2018) Correlation between disease activity of pediatric-onset systemic lupus erythematosus and level of vitamin D in Taiwan: a case-cohort study. J Microbiol Immunol Infect 51(1):110-114

33. Cutolo M, Otsa K, Paolino S, Yprus M, Veldi T, Seriolo B (2009) Vitamin D involvement in rheumatoid arthritis and systemic lupus erythaematosus. Ann Rheum Dis 68(3):446-447

34. Ben-Zvi I, Aranow C, Mackay M, Stanevsky A, Kamen DL, Marinescu LM et al (2010) The impact of vitamin D on dendritic cell function in patients with systemic lupus erythematosus. PLoS One 5(2):e9193

35. Toloza SMA, Cole DEC, Gladman DD, Ibanez D, Urowitz MB (2010) Vitamin D insufficiency in a large female SLE cohort. Lupus 19(1):13-19

36. Schoindre, Y., Jallouli, M., Tanguy, M. L., Ghillani, P., Galicier, L., Aumaitre, O., ... \& Limal, N. (2014). Lower vitamin D levels are associated with higher systemic lupus erythematosus activity, but not predictive of disease flare-up. Lupus science \& medicine.

37. Mok CC, Birmingham DJ, Ho LY, Hebert LA, Song H, Rovin BH (2012) Vitamin D deficiency as marker for disease activity and damage in systemic lupus erythematosus: a comparison with anti-dsDNA and anti-C1q. Lupus 21(1):36

38. Mandal M, Tripathy R, Panda AK, Pattanaik SS, Dakua S, Pradhan AK et al (2014) Vitamin D levels in Indian systemic lupus erythematosus patients: association with disease activity index and interferon alpha. Arthritis Res Therapy 16(1):R49

39. Bonakdar ZS, Jahanshahifar L, Jahanshahifar F, Gholamrezaei A (2011) Vitamin D deficiency and its association with disease activity in new cases of systemic lupus erythematosus. Lupus. 20(11):1155-1160

40. Nerviani, A., Mauro, D., Gilio, M., Grembiale, R. D., \& Lewis, M. J. (2018). To supplement or not to supplement? The rationale of vitamin $D$ supplementation in systemic lupus erythematosus. Open Rheumatol J, 12(1).

\section{Publisher's Note}

Springer Nature remains neutral with regard to jurisdictional claims in published maps and institutional affiliations. 